\title{
A method for verification of treatment times for high-dose-rate intraluminal brachytherapy treatment
}

\author{
Muhammad Asghar Gadhi',4, Shahab Fatmi², Muhammad Shakil ${ }^{3}$, Saeed Ahmad Buzdar ${ }^{4}$ \\ ${ }_{1}^{1}$ Department of Medical Physics, Bahawalpur Institute of Nuclear Medicine and Oncology (BINO), Bahawalpur, Pakistan \\ 2Department of Nuclear Medicine, Bahawalpur Institute of Nuclear Medicine and Oncology (BINO), Bahawalpur, Pakistan \\ ${ }^{3}$ Department of Physics, University of Gujrat, Gujrat, Pakistan \\ ${ }^{4}$ Medical Physics Research Group, Department of Physics, The Islamia University of Bahawalpur, Bahawalpur, Pakistan
}

Received November 16, 2015; Revised March 17, 2016; Accepted March 20, 2016; Published Online April 04, 2016

\section{Original Article}

\begin{abstract}
Purpose: This study was aimed to increase the quality of high dose rate (HDR) intraluminal brachytherapy treatment. For this purpose, an easy, fast and accurate patient-specific quality assurance (QA) tool has been developed. This tool has been implemented at Bahawalpur Institute of Nuclear Medicine and Oncology (BINO), Bahawalpur, Pakistan. Methods: ABACUS 3.1 Treatment planning system (TPS) has been used for treatment planning and calculation of total dwell time and then results were compared with the time calculated using the proposed method. This method has been used to verify the total dwell time for different rectum applicators for relevant treatment lengths $(2-7 \mathrm{~cm})$ and depths $(1.5-2.5 \mathrm{~cm})$, different oesophagus applicators of relevant treatment lengths $(6-10 \mathrm{~cm})$ and depths $(0.9$ \& $1.0 \mathrm{~cm})$, and a bronchus applicator for relevant treatment lengths $(4-7.5 \mathrm{~cm})$ and depth $(0.5 \mathrm{~cm})$. Results: The average percentage differences between treatment time $\mathrm{T}_{\mathrm{M}}$ with manual calculation and as calculated by the TPS is $0.32 \%$ (standard deviation $1.32 \%$ ) for rectum, $0.24 \%$ (standard deviation $2.36 \%$ ) for oesophagus and $1.96 \%$ (standard deviation $0.55 \%$ ) for bronchus, respectively. These results advocate that the proposed method is valuable for independent verification of patient-specific treatment planning QA. Conclusion: The technique illustrated in the current study is an easy, simple, quick and useful for independent verification of the total dwell time for HDR intraluminal brachytherapy. Our method is able to identify human error-related planning mistakes and to evaluate the quality of treatment planning. It enhances the quality of brachytherapy treatment and reliability of the system.
\end{abstract}

Keywords: Intraluminal; Brachytherapy; Independent Method; High Dose Rate

\section{Introduction}

The plan is to enhance the quality of intraluminal brachytherapy treatment. For this purpose, independent verification of total dwell time for individual patient is needed. The aim of current investigation is to develop an easy, accurate, simple and independent verification method for the authentication of treatment time of treatment planning system (TPS).

Brachytherapy is a vital part of radiotherapy for the malignancies of intralumen and is frequently used with external beam radiation therapy (EBRT) for radical/palliative treatment. Several studies have suggested that control rates are considerably enhanced with EBRT and brachytherapy ${ }^{1-4}$. High dose rate (HDR) remote after loading intraluminal brachytherapy has been commonly used all over the world ${ }^{4}$. The significance of independent verification of dosimetry earlier to HDR brachytherapy treatment delivery has been acknowledged universally. Thomadsen et al. recognized 44 errors in HDR brachytherapy treatment in data (1980-2001) from the Nuclear Regulatory Commission and International Atomic Energy Agency 5 Guidelines $^{6,7}$ recommended the independent confirmation about the procedures for a pre-treatment

\footnotetext{
Corresponding author: Muhammad Asghar Gadhi; Department of Medical Physics, Bahawalpur Institute of Nuclear Medicine and Oncology (BINO), Bahawalpur, Pakistan.
}

Cite this article as: Gadhi MA, Fatmi S, Shakil M, Buzdar SA. A method for verification of treatment times for high - dose - rate intraluminal brachytherapy treatment. Int J Cancer Ther Oncol. 2016; 4(2):423. DOI: 10.14319/ijcto.42.3 
review of the treatment planning system and the computer algorithms employed to calculate the dose distributions across the planning target volume (PTV). Techniques are required to be put into practice in order to reduce systematic and random errors in planning and treatment procedures as well. The input to treatment planning system can be provided with multimodality images (i.e. CT/MRI/Orthogonal X-rays/Ultrasound) and this software, enabled the medical physicists to maximize the dose uniformity, whilst minimizing the implant volume required to cover the target volume sufficiently as well as lessens the dose to the organs at risk. Such flexibility makes a challenge for the medical physicists for the confirmation of the optimized treatment time with manual calculation technique, which takes only a few minutes while providing a high probability of noticing considerable mistakes/errors. Actually, patients are often have to wait for the duration of treatment planning with an applicator introduced by a radiation oncologist and there is a huge amount of time pressure on the planning procedure. During that time, errors/mistakes and miscommunications may easily happened. To detect these errors, the need of patient-specific QA as well as independent verification of the key treatment planning parameter (i.e. time) are obvious and have to be performed rapidly and easily to ensure the safety and accuracy of the treatment.

The literature has reported independent authentication techniques for external beam radiation therapy ${ }^{8}$ and HDR brachytherapy treatment planning. A number of techniques for inspection of a brachytherapy treatment plan were reported. Various methods check on single-implant ${ }^{9-12}$ or double- implants ${ }^{13},{ }^{14}$. Some verify intracavitary gynecological treatments ${ }^{11,12,15,16}$, volume implants ${ }^{17-21}$ and endobronchial brachytherapy ${ }^{13,14}$. Recently many investigators have developed in-house software to compute the dose at arbitrary points 22-24. Such software may be helpful for the commissioning of TPS, in medical practice, human errors in individual treatment planning in radiotherapy will not be recognized because of the use of the similar coordinate system, digitized applicator paths and dose point coordinates as those in the treatment planning system.

Although sufficient literature is available for verification of treatment planning time but only few studies ${ }^{\mathbf{1 3}, 14}$ are available for bronchus brachytherapy and no literature regarding rectum and oesophagus was found. It was aimed to introduce intraluminal (oesophagus, bronchus and rectum) brachytherapy in our institute. This paper presents a very quick, simple and easy patient-specific independent verification method of the treatment time (sum of all dwell times) for intraluminal brachytherapy applicators. The time needed for confirmation is in the order of 10-15 seconds if an Excel spreadsheet is available otherwise 1-2 minutes, despite the nature of applicator. A negligible additional waiting time for the patient is needed for this verification process but it provides a valuable independent confirmation.

\section{Methods and Materials}

Bahawalpur Institute of Nuclear Medicine and Oncology has started radiotherapy in 1998 and HDR brachytherapy was made available in October 2004. Gynecological and surface malignancies are being treated with brachytherapy. It was intended to extend our services to other sites i.e. rectum, oesophagus and bronchus. For this purpose, authentication of treatment time as calculated by TPS is needed.

ABACUS 3.1 TPS, manufactured by Varian Medical Solutions, USA is used for the current investigations. The method proposed here is therefore intended to harmonize with the ABACUS 3.1 (but it is equally applicable to other TPS, like Plato TPS etc. and off course universal in nature). All dosimetric calculations were performed for a nominal $37 \mathrm{GBq}(10 \mathrm{Ci}$ ) source strength and 7 Gy as prescribed doses; it can be used for other source strengths and prescribed doses. ABACUS 3.1 has been used for treatment planning and calculation of total nominal time first and then results were compared with proposed method. Treatment planning for intraluminal (oesophagus, bronchus and rectum) brachytherapy using different available applicators was aimed to be verified with the manual planning. The factors required for the calculation are the prescribed dose, the depth of dose prescription, the length of dose prescription and source strength.

Dose delivery time was calculated manually with the equation;

$T_{M}=\frac{\left(R_{L}\right) *(\text { ElongationFactor }) *(60 \mathrm{~min} / \text { hour }) *(60 \mathrm{sec} / \mathrm{min}) * \text { Dose }}{(\text { Activity }) *(\mathrm{mg} / \mathrm{mCi}) * 10^{6}}$

This equation was derived from Johns et al. ${ }^{25}$ by using long and away tables and converted to Iridium based on the exposure rate constant, which indicated that the manual calculation of time requires some values as input. These values i.e. $\mathrm{R}_{\mathrm{L}}$ and elongation factor have been derived from Johns et al. ${ }^{25}$ using Table 13.3 and Figure 13.5. The $\mathrm{R}_{\mathrm{L}}$ is the mg.hr to deliver 1000 rads to a point $\mathrm{h} \mathrm{cm}$ from the center of a linear source of active length L. From Table 13.325, find the value of length in first column and then go right in the corresponding row, where it intersects the corresponding treatment distance that value is for $\mathrm{R}_{\mathrm{L}}$. The elongation factor has been determined by taking the ratio of the length of treatment/ distance of treatment (ratio of $\mathrm{L} / \mathrm{h}$ ). Then using Figure $13.5^{25}$ (that looks like a Gaussian curve at the bottom of the page) ratio of $\mathrm{L} / \mathrm{h}$ vs percent increase is obtained and go straight up on the graph, and look across for the percent increase in the value. Then the value we get, suppose it was 16 on the y-axis, the elongation factor is going to be 1.16 because it is a percentage increase of dose due to lateral scatter, and contribution from surrounding sources. The conversion 
factor from Radium-226 to Iridium-192 is $\mathrm{mg} / \mathrm{mCi}=$ 0.5648. The applicators available at XINO for rectum, esophagus and bronchus manufactured by Varian Medical Solution, USA and are compatible with Gamma Med plus HDR unit and ABACUS 3.1 TPS have been used for this study as shown in Figure 1. MS Excels, SPSS 16.0 have been used for data analysis. EndNote 5 has been used for reference management.

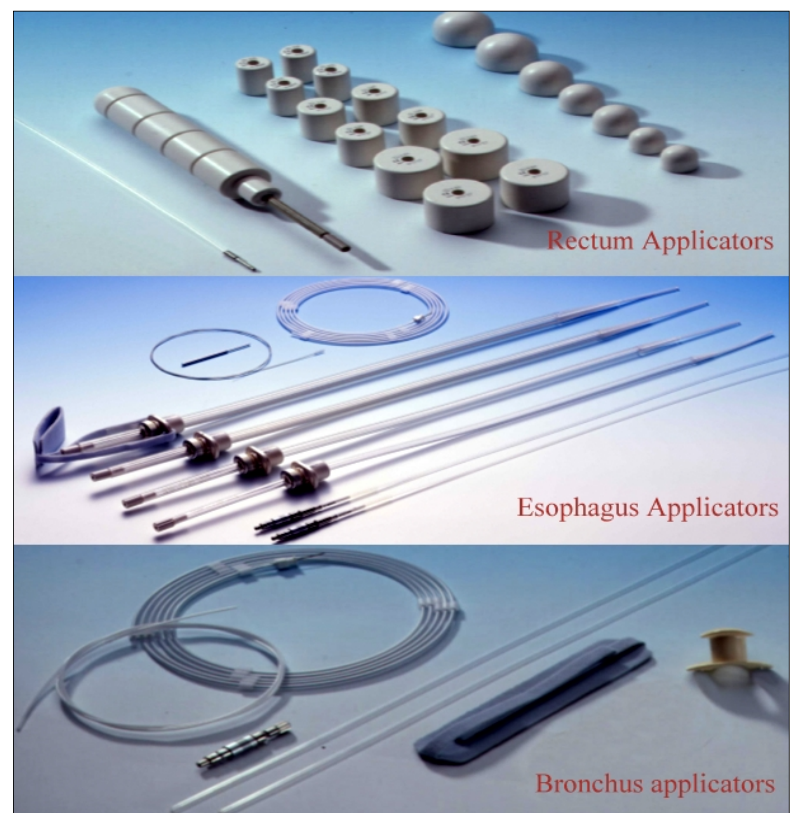

Figure 1: Different applicators for rectum, esophagus and bronchus.

\subsection{Method's evaluation}

To evaluate the proposed method for clinical use and validation of TPS for intraluminal applications, it was used to verify the total dwell time for three different diameters $(2,3$ and $4 \mathrm{~cm})$ rectum applicators for clinical relevant treatment lengths $(2.0,2.5,3.0,3.5,4.0,4.5,5.0$, $5.5,6.0,6.5$, and $7.0 \mathrm{~cm})$ and treatment depths $(1.5,2.0$, and 2.5), three different diameters $(8,10$ and $12 \mathrm{~mm})$ oesophagus applicators for clinical relevant treatment lengths $(6.0,6.5,7.0,7.5,8.0,8.5,9.0,9.5$ and $10.0 \mathrm{~cm})$ and treatment depths $(0.9$ and $1.0 \mathrm{~cm})$, and one $(5 \mathrm{~mm}$ diameter) bronchus applicator for clinical relevant treatment lengths $(4.0,4.5,5.0,5.5,6.0,6.5,7.0$ and 7.5 $\mathrm{cm})$ and treatment depth $(0.5 \mathrm{~cm})$ are available at BINOXINO.

\section{Results}

The objective was to confirm the total nominal time calculated by means of ABACUS TPS with the help of manual method, for different treatment lengths and treatment depths by developing and implementing a fast and accurate secondary dose calculation technique for QA of HDR treatment planning. For $10 \mathrm{Ci}$ activity of Iridium-192 and 0.5648 conversion factor (Radium to Iridium), the treatment time comparison for different applicators available for rectum, esophagus and bronchus as well as percentage difference between the results of both methods for different diameters, treatment depths and lengths have been calculated and results are presented in the tables 1-3. The average percentage difference between treatment time $\mathrm{T}_{\mathrm{M}}$ with manual calculation and as calculated by the TPS was $0.32 \%$ (standard deviation $1.32 \%$ ) for rectum, $0.24 \%$ (standard deviation 2.36\%) for oesophagus and 1.96\% (standard deviation $0.55 \%$ ) for bronchus, respectively.

Comparison between the treatment times as calculated by TPS and manual method for different rectum, oesophagus and bronchus applicators are graphically depicted in figures 2-4 respectively.

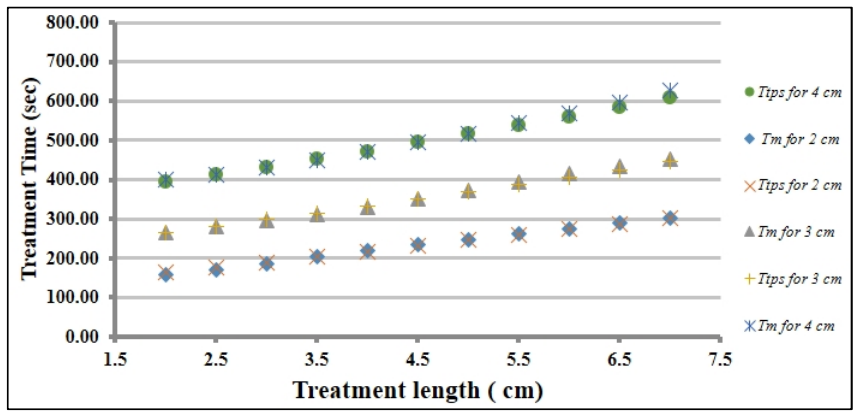

Figure 2: Comparison between the treatment times as calculated by TPS and manual method for different rectum applicators.

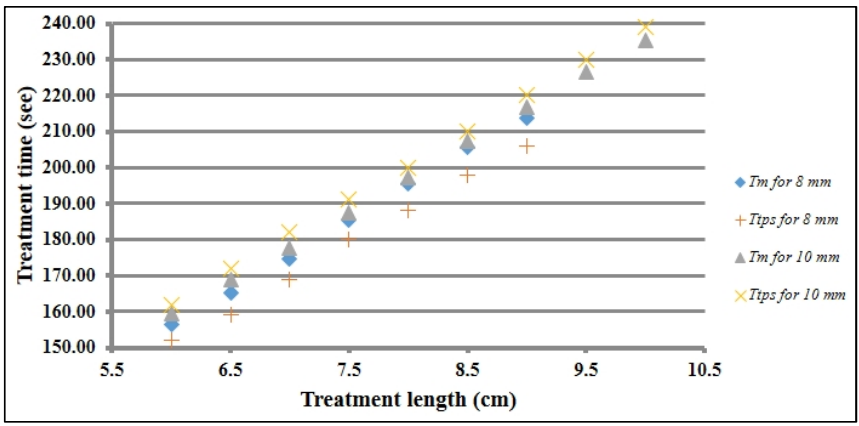

Figure 3: Comparison between the treatment times as calculated by TPS and manual method for different esophagus applicators.

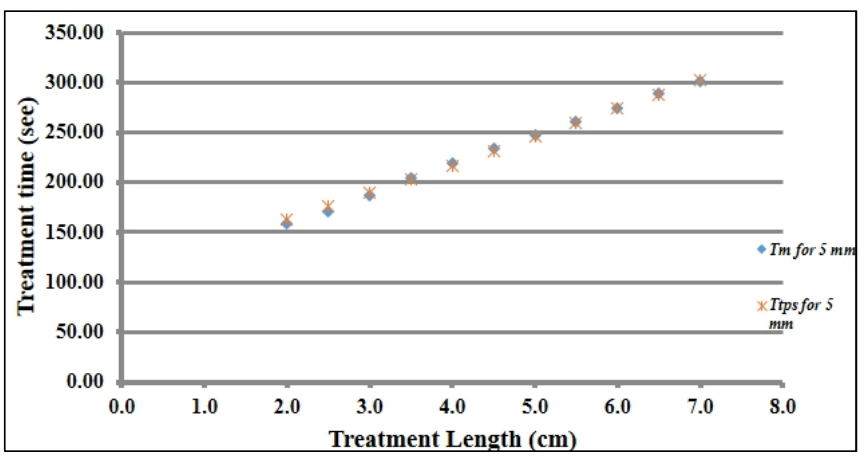

Figure 4: Comparison between the treatment times as calculated by TPS and manual method for different bronchus applicators. 
Table 1: Percentage difference between total nominal time calculated by the manual method and Abacus 3.1 for available rectum applicators.

\begin{tabular}{|c|c|c|c|c|c|c|c|}
\hline $\begin{array}{c}\text { Treatment } \\
\text { Length } \\
\text { L (cm) }\end{array}$ & $\begin{array}{c}\text { Ratio } \\
\mathrm{L} / \mathrm{h}\end{array}$ & $\begin{array}{c}\text { Elongation } \\
\text { Factor }\end{array}$ & $\mathrm{R}_{\mathrm{L}}$ & $\begin{array}{c}\text { Prescribed } \\
\text { dose (Gy) }\end{array}$ & $\begin{array}{c}\mathrm{T}_{\mathrm{M}} \\
\text { (see) }\end{array}$ & $\begin{array}{c}\mathrm{T}_{\text {TPS }} \\
\text { (See) }\end{array}$ & $\begin{array}{c}\% \\
\text { Difference }\end{array}$ \\
\hline \multicolumn{8}{|c|}{$2.0 \mathrm{~cm}$ dia Rectum applicator, $1.5 \mathrm{~cm}$ Treatment height (depth) } \\
\hline 2.0 & 1.33 & 1.110 & 320.0 & 7.0 & 158.48 & 163 & -2.85 \\
\hline 2.5 & 1.67 & 1.130 & 340.0 & 7.0 & 171.42 & 176 & -2.67 \\
\hline 3.0 & 2.00 & 1.145 & 365.0 & 7.0 & 186.47 & 190 & -1.89 \\
\hline 3.5 & 2.33 & 1.170 & 391.0 & 7.0 & 204.11 & 203 & 0.54 \\
\hline 4.0 & 2.67 & 1.180 & 417.0 & 7.0 & 219.55 & 217 & 1.16 \\
\hline 4.5 & 3.00 & 1.180 & 444.0 & 7.0 & 233.76 & 231 & 1.18 \\
\hline 5.0 & 3.33 & 1.180 & 471.0 & 7.0 & 247.98 & 246 & 0.80 \\
\hline 5.5 & 3.67 & 1.170 & 500.5 & 7.0 & 261.27 & 260 & 0.49 \\
\hline 6.0 & 4.00 & 1.160 & 530.0 & 7.0 & 274.31 & 274 & 0.11 \\
\hline 6.5 & 4.33 & 1.160 & 559.0 & 7.0 & 289.32 & 288 & 0.46 \\
\hline 7.0 & 4.67 & 1.150 & 588.0 & 7.0 & 301.70 & 303 & -0.43 \\
\hline \multicolumn{8}{|c|}{$3.0 \mathrm{~cm}$ dia Rectum applicator, $2.0 \mathrm{~cm}$ Treatment height (depth) } \\
\hline 2.0 & 1.00 & 1.085 & 546.0 & 7.0 & 264.32 & 265 & -0.26 \\
\hline 2.5 & 1.25 & 1.100 & 569.0 & 7.0 & 279.26 & 281 & -0.62 \\
\hline 3.0 & 1.50 & 1.120 & 594.0 & 7.0 & 296.83 & 298 & -0.39 \\
\hline 3.5 & 1.75 & 1.130 & 620.0 & 7.0 & 312.59 & 315 & -0.77 \\
\hline 4.0 & 2.00 & 1.135 & 650.0 & 7.0 & 329.17 & 333 & -1.16 \\
\hline 4.5 & 2.25 & 1.150 & 684.0 & 7.0 & 350.96 & 351 & -0.01 \\
\hline 5.0 & 2.50 & 1.165 & 718.0 & 7.0 & 373.21 & 369 & 1.13 \\
\hline 5.5 & 2.75 & 1.170 & 752.0 & 7.0 & 392.56 & 388 & 1.16 \\
\hline 6.0 & 3.00 & 1.180 & 789.0 & 7.0 & 415.40 & 406 & 2.26 \\
\hline 6.5 & 3.25 & 1.180 & 826.0 & 7.0 & 434.88 & 426 & 2.04 \\
\hline 7.0 & 3.50 & 1.175 & 864.0 & 7.0 & 452.96 & 445 & 1.76 \\
\hline \multicolumn{8}{|c|}{$4.0 \mathrm{~cm}$ dia Rectum applicator, $2.5 \mathrm{~cm}$ Treatment height (depth) } \\
\hline 2.0 & 0.80 & 1.080 & 830.0 & 7.0 & 399.95 & 393 & 1.74 \\
\hline 2.5 & 1.00 & 1.085 & 851.0 & 7.0 & 411.97 & 411 & 0.24 \\
\hline 3.0 & 1.20 & 1.100 & 877.0 & 7.0 & 430.43 & 431 & -0.13 \\
\hline 3.5 & 1.40 & 1.110 & 905.0 & 7.0 & 448.21 & 451 & -0.62 \\
\hline 4.0 & 1.60 & 1.122 & 943.0 & 7.0 & 472.07 & 472 & 0.02 \\
\hline 4.5 & 1.80 & 1.130 & 980.0 & 7.0 & 494.09 & 494 & 0.02 \\
\hline 5.0 & 2.00 & 1.135 & 1018.0 & 7.0 & 515.52 & 516 & -0.09 \\
\hline 5.5 & 2.20 & 1.150 & 1060.0 & 7.0 & 543.89 & 539 & 0.90 \\
\hline 6.0 & 2.40 & 1.160 & 1101.0 & 7.0 & 569.84 & 561 & 1.55 \\
\hline 6.5 & 2.60 & 1.170 & 1145.0 & 7.0 & 597.72 & 585 & 2.13 \\
\hline 7.0 & 2.80 & 1.180 & 1189.0 & 7.0 & 625.99 & 609 & 2.71 \\
\hline
\end{tabular}

Table 2: Percentage difference between total nominal time calculated by the manual method and Abacus 3.1 for available bronchus applicator.

\begin{tabular}{|c|c|c|c|c|c|c|c|}
\hline $\begin{array}{l}\text { Treatment } \\
\text { Length L }(\mathrm{cm})\end{array}$ & $\begin{array}{l}\text { Ratio } \\
\mathrm{L} / \mathrm{h}\end{array}$ & $\begin{array}{l}\text { Elongation } \\
\text { factor }\end{array}$ & $\mathrm{R}_{\mathrm{L}}$ & $\begin{array}{c}\text { Prescribed } \\
\text { dose (Gy) }\end{array}$ & $\begin{array}{l}\mathrm{T}_{\mathrm{M}} \\
\text { (see) }\end{array}$ & $\begin{array}{l}\mathrm{T}_{\mathrm{TPS}} \\
\text { (See) }\end{array}$ & $\begin{array}{c}\% \\
\text { Difference }\end{array}$ \\
\hline \multicolumn{8}{|c|}{$5 \mathrm{~mm}$ dia Bronchial applicator, $0.75 \mathrm{~cm}$ Treatment height (depth) } \\
\hline 4.0 & 5.33 & 1.145 & 163.0 & 7.0 & 83.27 & 85 & -2.08 \\
\hline 4.5 & 6.00 & 1.130 & 179.0 & 7.0 & 90.25 & 92 & -1.94 \\
\hline 5.0 & 6.67 & 1.110 & 195.0 & 7.0 & 96.57 & 99 & -2.51 \\
\hline 5.5 & 7.33 & 1.095 & 212.0 & 7.0 & 103.58 & 106 & -2.34 \\
\hline 6.0 & 8.00 & 1.095 & 228.0 & 7.0 & 111.39 & 113 & -1.44 \\
\hline 6.5 & 8.67 & 1.090 & 244.0 & 7.0 & 118.66 & 121 & -1.97 \\
\hline 7.0 & 9.33 & 1.085 & 260.0 & 7.0 & 125.87 & 127 & -0.90 \\
\hline 7.5 & 10.00 & 1.070 & 276.0 & 7.0 & 131.76 & 135 & -2.46 \\
\hline
\end{tabular}


Table 2: Percentage difference between total nominal time calculated by the manual method and Abacus 3.1 for available esophagus applicators.

\begin{tabular}{|c|c|c|c|c|c|c|c|}
\hline $\begin{array}{l}\text { T. Length } \\
\mathrm{L}(\mathrm{cm})\end{array}$ & $\begin{array}{l}\text { Ratio } \\
\mathrm{L} / \mathrm{h}\end{array}$ & $\begin{array}{c}\text { Elongation } \\
\text { factor }\end{array}$ & $\mathrm{R}_{\mathrm{L}}$ & $\begin{array}{c}\text { Prescribed } \\
\text { dose (Gy) }\end{array}$ & $\begin{array}{l}\mathrm{T}_{\mathrm{M}} \\
\text { (see) }\end{array}$ & $\begin{array}{c}\mathrm{T}_{\mathrm{TPS}} \\
(\mathrm{See}) \\
\end{array}$ & $\begin{array}{c}\% \\
\text { Difference }\end{array}$ \\
\hline \multicolumn{8}{|c|}{$8 \mathrm{~mm}$ dia Esophagus applicator, $0.9 \mathrm{~cm}$ Treatment height (depth) } \\
\hline 6.0 & 6.67 & 1.110 & 316.0 & 7.0 & 156.50 & 152 & 2.88 \\
\hline 6.5 & 7.22 & 1.095 & 338.0 & 7.0 & 165.13 & 159 & 3.71 \\
\hline 7.0 & 7.78 & 1.090 & 359.0 & 7.0 & 174.59 & 169 & 3.20 \\
\hline 7.5 & 8.33 & 1.088 & 382.0 & 7.0 & 185.44 & 180 & 2.93 \\
\hline 8.0 & 8.89 & 1.085 & 404.0 & 7.0 & 195.58 & 188 & 3.87 \\
\hline 8.5 & 9.44 & 1.082 & 426.0 & 7.0 & 205.66 & 198 & 3.72 \\
\hline 9.0 & 10.00 & 1.070 & 448.0 & 7.0 & 213.88 & 206 & 3.68 \\
\hline \multicolumn{8}{|c|}{$10 \mathrm{~mm}$ dia Esophagus applicator, $1.0 \mathrm{~cm}$ Treatment height (depth) } \\
\hline 6.0 & 6.0 & 1.130 & 316.0 & 7.0 & 159.32 & 162 & -1.68 \\
\hline 6.5 & 6.5 & 1.120 & 338.0 & 7.0 & 168.90 & 172 & -1.83 \\
\hline 7.0 & 7.0 & 1.110 & 359.0 & 7.0 & 177.80 & 182 & -2.36 \\
\hline 7.5 & 7.5 & 1.100 & 382.0 & 7.0 & 187.48 & 191 & -1.88 \\
\hline 8.0 & 8.0 & 1.095 & 404.0 & 7.0 & 197.38 & 200 & -1.33 \\
\hline 8.5 & 8.5 & 1.090 & 426.0 & 7.0 & 207.18 & 210 & -1.36 \\
\hline 9.0 & 9.0 & 1.085 & 448.0 & 7.0 & 216.88 & 220 & -1.44 \\
\hline 9.5 & 9.5 & 1.08 & 470.0 & 7.0 & 226.48 & 230 & -1.55 \\
\hline 10.0 & 10.0 & 1.07 & 493.0 & 7.0 & 235.36 & 239 & -1.55 \\
\hline \multicolumn{8}{|c|}{$12 \mathrm{~mm}$ dia Esophagus applicator, $1.0 \mathrm{~cm}$ Treatment height (depth) } \\
\hline 6.0 & 6.00 & 1.130 & 316.0 & 7.0 & 159.32 & 162 & -1.68 \\
\hline 6.5 & 6.50 & 1.120 & 338.0 & 7.0 & 168.90 & 172 & -1.83 \\
\hline 7.0 & 7.00 & 1.110 & 359.0 & 7.0 & 177.80 & 182 & -2.36 \\
\hline 7.5 & 7.50 & 1.100 & 382.0 & 7.0 & 187.48 & 191 & -1.88 \\
\hline 8.0 & 8.00 & 1.095 & 404.0 & 7.0 & 197.38 & 200 & -1.33 \\
\hline 8.5 & 8.50 & 1.090 & 426.0 & 7.0 & 207.18 & 210 & -1.36 \\
\hline 9.0 & 9.00 & 1.085 & 448.0 & 7.0 & 216.88 & 220 & -1.44 \\
\hline 9.5 & 9.50 & 1.08 & 470.0 & 7.0 & 226.48 & 230 & -1.55 \\
\hline 10.0 & 10.00 & 1.07 & 493.0 & 7.0 & 235.36 & 239 & -1.55 \\
\hline
\end{tabular}

\section{Discussion}

The results of the proposed method are in reasonably good agreement with previously published work ${ }^{9}$. In the literature, the reported correctness of manually calculated treatment time vary from 1\% (one single catheter ${ }^{9}$ ) through $5 \%$ (volume implant ${ }^{20}$ ) up to $10 \%$ (planar implants ${ }^{19}$ ). The results of the present study are comparable to the literature 9 .

The figures 2-4 show that the treatment time as calculated by both techniques is closely matched. Treatment time was increased with the increase in treatment length or depth or both.

The technique illustrated in the current study is a simple, quick and useful for HDR intraluminal brachytherapy (rectum, esophagus and bronchus) that needs no particular expertise for example developing TG43-based in-house software to verify the dose calculation i.e. the total treatment time to deliver the prescribed dose earlier to each treatment. It requires approximately one minute and hence does not considerably lengthen the patient's waiting time. The key usefulness of the second check philosophy employed in the present investigation is to gain confidence that the dose calculation is correct. Although the accurateness of dose computations is completely confirmed upon commissioning and during periodic quality assurance tests, checking the dose delivery time prior to each treatment guarantees that the correct treatment depth, treatment length, prescribe dose and the correct activity (source strength) are being used and that any bug (known or unknown) in the planning software did not affect the dose calculation.

Treatment planning is a complex as well as a time taking process in radiotherapy in general and in brachytherapy in particular that includes the applicator insertion, a complex simulation, CT/MRI or Orthogonal radiograph, transfer of simulation data to treatment planning system and then the best possible treatment plan for an individual patient. Each step is prone to one or more sources of error, so it is essential to be performed with the greatest accuracy achievable. The ambiguity in each step may influence the accuracy of subsequent steps and, therefore can have an impact on the overall treatment time. Confirmation of the total dwell time by an independent method certainly ensures the accuracy, reliability and authenticity of all component processes.

Despite its great simplicity, our method is capable to identify human error-related planning mistakes, and to evaluate the quality of treatment planning. Numerous 
other independent confirmation techniques for individual treatment planning have been presented. Kumar et al. presented an in-house method, which calculates the dose at arbitral points ${ }^{22}$. Lachaine et al. also presented an in-house technique, which completes very quick calculation of point dose ${ }^{23}$. Such kinds of techniques are probably to be valuable in the commissioning of treatment planning systems and partially in individual treatment planning QA too. Though, since these methods make use of the same Cartesian coordinate system, digitized applicator paths and dose point coordinates as in the treatment planning system, they are incapable to notice human errors related with the treatment planning process, for instance set of prescription point with the incorrect coordinate, the wrong digitization of applicators, erroneous dose points or applicator points, inappropriate magnification of simulation films, or utilization of an unintended size or arrangement of applicators.

\section{Conclusion}

Verification of the accuracy of optimized calculations with confirmation, evaluation method is fundamental in order to guarantee the quality of treatment. This independent verification tool for confirmation of the total dwell time in TPS plan of intraluminal HDR brachytherapy presents a solid base to apply the plan for brachytherapy treatment. The average percentage differences between treatment time $\mathrm{T}_{\mathrm{M}}$ with manual calculations and as calculated by the TPS is $0.32 \%$ (standard deviation $1.32 \%$ ) for rectum, $0.24 \%$ (standard deviation $2.36 \%$ ) for esophagus and $1.96 \%$ (standard deviation $0.55 \%$ ) for bronchus, respectively. These results advocate that the proposed method is valuable for independent verification of patient-specific treatment planning $\mathrm{QA}$. In conclusion, we have developed a very simple, trouble-free, fast and independent verification technique for intraluminal brachytherapy. It enhances the quality of brachytherapy treatment and reliability of the system.

\section{Conflict of interest}

The authors declare that they have no conflicts of interest. The authors alone are responsible for the content and writing of the paper.

\section{Acknowledgement}

The authors acknowledge the role of Higher Education Commission, Pakistan and Pakistan Atomic Energy Commission for providing the opportunity to conduct the study.

\section{References}

1. Lindel K. Interventional radiotherapy or brachytherapy: new challenges for a successful technique. $2^{\text {nd }}$ Annual Conference of Bangladesh Medical Physics Society. Int J Cancer Ther Oncol. 2013;1(1).

2. Lanciano RM, Martz K, Coia LR, Hanks GE. Tumor and treatment factors improving outcome in stage III-B cervix cancer. Int J Radiat Oncol Biol Phys. 1991;20(1):95-100.

3. Montana GS, Wesley CF, Varia MA, et al. Carcinoma of the Cervix, Stage III, Results of radiation therapy. Cancer 1986; 57: 148-54.

4. Halperin EC, Brady LW, Perez CA, Wazer DE. Perez \& Brady's Principles and Practice of Radiation Oncology, Chapter 25, $6^{\text {th }}$ Edition. Lippincott Williams \& Wilkins: 2013.

5. Thomadsen B, Lin SW, Laemmrich $\mathrm{P}$, et al. Analysis of treatment delivery errors in brachytherapy using formal risk analysis techniques. Int J Radiat Oncol Biol Phys. 2003;57:1492-508.

6. Towards Safer Radiotherapy. British Institute of Radiology. Institute of Physics and Engineering in Medicine, National Patient Safety Agency, Society and College of Radiographers. The Royal College of Radiologists, London, 2007.

7. Kubo HD, Glasgow GP, Pethel TD, et al. High dose-rate brachytherapy treatment delivery: report of the AAPM Radiation Therapy Committee Task Group No. 59. Medical physics. 1998; 25(4): 375-403.

8. Quino LV, Huerta-Hernandez C, Papanikolaou $\mathrm{N}$, et al. A Monte Carlo model for independent dose verification in IMRT and VMAT for the Varian Novalis TX with high definition MLC. Int J Cancer Ther Oncol. 2015;3(3):3312.

9. Kubo H. Verification of treatment plans by mathematical formulas for single catheter HDR brachytherapy. Med Dosim. 1992;17(3):151-5.

10. Rogus RD, Smith MJ, Kubo HD. An equation to QA check the total treatment time for single-catheter HDR brachytherapy. Int J Radiat Oncol Biol Phys. 1998;40(1):245-8.

11. Mayo CS, Ulin K. A method for checking high dose rate treatment times for vaginal applicators. J Appl Clin Med Phys. 2001; 2(4):184-90.

12. Buzdar SA, Gadhi MA, Rao MA, et al. Verification of computerized treatment planning for HDR 192Ir brachytherapy for gynaecological cancer. J Pak Med Assoc. 2009;59(2):113-5.

13. Miller AV, Davis MG, Horton JL. A method for verifying treatment times for simple high-dose-rate endobronchial brachytherapy procedures. Med Phys. 1996;23(11):1903-8.

14. Ezzell GA. A manual algorithm for computing dwell times for two-catheter endobronchial 
treatments using HDR brachytherapy. Med Phys. 2000;27(5):1030-3.

15. Thomadsen BR, Shahabi S, Stitt JA, et al. High dose rate intracavitary brachytherapy for carcinoma of the cervix: the Madison system: II. Procedural and physical considerations. Int J Radiat Oncol Biol Phys. 1992;24(2):349-57.

16. Das RK, Bradley KA, Nelson IA, et al. Quality assurance of treatment plans for interstitial and intracavitary high-dose-rate brachytherapy. Brachytherapy. 2006; 5(1):56-60.

17. Murrer L, Kolkman-Deurloo IK. Manual calculation of treatment time for high dose rate brachytherapy with a flexible intraoperative template (FIT). Phys Med Biol. 2001;46(4):1075-84.

18. Huckle A, Al-Qaisieh B, Bownes P. Methods of verifying the output of the treatment planning system used for high dose rate (HDR) prostate brachytherapy. Radiother Oncol. 2012;103(2):261-5.

19. Ezzell GA. Quality assurance of treatment plans for optimized high dose rate brachytherapy--planar implants. Med Phys. 1994;21(5):659-61.
20. Venselaar JL, Bierhuizen HW, Klop R. A method to check treatment time calculations in Ir-192 high-dose-rate volume implants. Med Phys. 1995;22(9):1499-500.

21. Hadad K, Ganapol BD, Hamilton R, Watchman C. Dose verification for accelerated partial breast irradiation. International Conference on Advances in Mathematics, Computational Methods \& Reactor Physics; Saratoga Springs, NY; 2009.

22. Kumar R, Sharma SD, Vijaykumar C, et al. A dose verification method for high-dose-rate brachytherapy treatment plans. J Cancer Res Ther. 2008;4(4):173-7.

23. Lachaine ME, Gorman JC, Palisca MG. A fast, independent dose check of HDR plans. J Appl Clin Med Phys. 2003;4(2):149-55.

24. Cohen GN, Amols HI, Zaider M. An independent dose-to-point calculation program for the verification of high-dose-rate brachytherapy treatment planning. Int J Radiat Oncol Biol Phys. 2000;48(4):1251-8.

25. Johns HE, Cunningham JR. Physics of radiology, $4^{\text {th }}$ Edition Chapter 13, 1983. 